\title{
ДОКАЗЫВАНИЕ ПРОЦЕССУАЛЬНЫХ ЮРИДИЧЕСКИХ ФАКТОВ, КАК СОСТАВЛЯЮЩЕЙ ПРОЦЕССУАЛЬНОГО ПОВЕДЕНИЯ ЛИЦ, УЧАСТВУЮЩИХ В ДЕЛЕ
}

\section{PROVING PROCEDURAL LEGAL FACTS AS A COMPONENT OF THE PROCEDURAL BEHAVIOR OF PERSONS PARTICIPATING IN THE CIVIL PROCEDURE}

Ya. Rokotyanskaya

Summary. To pay attention to the proof of procedural legal facts as a component of the procedural behavior of persons participating in the civil procedure, to study the positions of scientists on the issues of proving procedural legal facts in civil proceedings. Both General scientific methods such as analysis, synthesis, induction and deduction were used in the work, as well as legal methods proper - the method of comparative law, jurico-dogmatic. The author substantiates the possibility of all the actions of a person in the process to be formed into procedural behavior, and also the possibility of their implementation in evidence. In the course of the study, the author came to the conclusion that all the actions of a person in the process form a procedural behavior in their entirety, and are most often embodied in evidence. However, it is worth noting that they can also be embodied in several acts of behavior of a person at once. Also, the evidentiary value of procedural behavior can acquire only with the active role of the opposite party.

Keywords: procedural legal facts; procedural behavior; civil proceedings; proof; proof; evidentiary value procedural behavior; civil procedural law.
Д о недавнего времени теме процессуальных юридических фактов не придавалось должного внимания, так последним комплексным исследованием данной области являются труды Яркова В.В. тем не менее, в настоящая время данная тема с проведением реформирования судопроизводства [1] не теряет своей актуальности. Также, стоит отметить, о возможном внедрении технологии искусственного интеллекта в гражданский процесс и переходе к электронному правосудию. Указанное выше говорит о необходимости исследования данной темы, и выработку новых подходов к понятию, значению, доказыванию и другим вопросам, связанным с процессуальными юридическими фактами.

В работе использованы общенаучные методы анализа и синтеза. Также в работе использованы собственно

\author{
Рокотянская Яна Александровна \\ Аспирант, Российский государственный \\ университет правосудия \\ 7726299@mail.ru
}

Аннотация. Обратить внимание на доказывание процессуальных юридических фактов, как составляющей процессуального поведения лиц, участвующих в деле, изучить позиции ученых по вопросам доказывания процессуальных юридических фактов в гражданском судопроизводстве. В работе были использованы как общенаучные методы, такие как анализ, синтез, индукция и дедукция, так и собственно юридические методы метод сравнительного правоведения, юрико-догматический. Автор обосновывает возможность всех действий лица в процессе образовываться в процессуальное поведение, и также возможность их воплощения в доказательства. В ходе исследования автор пришел к выводу 0 том, что все действия лица в процессе образуют в своей совокупности процессуальное поведение, и чаще всего воплощаются в доказательствах. Однако стоит заметить, что они также могут воплощаться сразу в нескольких актах поведения лица. Также доказательственное значение процессуальное поведение может приобретать только при активной роли противоположной стороны.

Ключевые слова: процессуальные юридические факты; процессуальное поведение; гражданское судопроизводство; доказывание; доказательства; доказательственное значение процессуальное поведение; гражданское процессуальное право.

юридические методы, метод сравнительного правоведения для оценки уже имеющихся статей Гражданского процессуального кодекса Российской Федерации, регулирующих гражданские процессуальные правоотношения.

Поскольку тема доказывания процессуальных юридических фактов не нова для процесса, несмотря на ее актуальность даже в наше время, трудов по данной тематике достаточно не много. В ходе изучения указанной темы были исследованы работы: Ярков В.В., Боннер А.Т., Фокина М.А., Осипов Ю.К, Рожкова М.А., Кукуев С.Ю., Исаенкова О.В., Болтуев С.Ш.

Процессуальные юридические факты могут, как входить в предмет доказывания, так и составлять отдельный локальный предмет доказывания, являющийся 
предпосылкой и основой для совершения определенного процессуального действия. Однако стоит сказать, что процессуальный юридический факт и в отдельности имеет вполне весомое значение.

Например, если ответчик требует назначения экспертизы на предмет установления подлинности своей подписи в спорном документе, а впоследствии (с учетом своих изменившихся интересов) вдруг предъявляет встречный иск, основанный на таком документе, то суд, помимо отказа в удовлетворении ходатайства об экспертизе, может прийти к выводу, что ответчик признал факт подписания им спорного документа.

В данной ситуации присутствует некое процессуальное указание в виде совершения процессуального действия одной из сторон на действительное положение фактов, что помогает суду установить истинный характер дела и, соответственно, принять правосудное решение. Особенность таких процессуальных «поступков» также заключается в том, что они фиксируются в соответствующих процессуальных документах, что предопределяет их значение и придает статус письменного доказательства.

Итак, в своей совокупности процессуальные действия, совершенные определенным субъектом, представляют собой совокупность процессуальных юридических фактов. Эта совокупность представляет собой цепочку процессуальных действий участника процесса. Такое явление было наиболее полно разработано наукой уголовного процесса и там получило название «улики поведения» [2. с. 5]. В науке гражданского процесса уже была попытка экстраполяции и адаптации данного понятия из науки уголовного процесса.

Более того, думается, было достаточно удачно адаптировано и определено понятие «процессуальное поведение». Тем не менее несмотря на многие положительные тенденции, глубокой научной разработки данного понятия представлено не было. Помимо всего прочего, структура и элементы данного понятия также не были описаны достаточно подробно.

Понятие «процессуальное поведение» хотя и не тождественно, однако очень близкое по значению с понятием «улики поведения» с той лишь разницей, что под «уликами поведения» понимается не только действия обвиняемого, подозреваемого в рамках уголовного процесса, но и на протяжении всего уголовного судопроизводства, и даже до момента возбуждения уголовного дела.

Что касается доказательственного значения процессуального поведения лиц, то существует несколь- ко мнений. Так, Курылев С.В. отмечает, что «предметом непосредственного познания могут оказаться ... процессуальные действия сторон, являющиеся актами распоряжения объектом процесса и процессуальными средствами его защиты - отказ от иска, мировое соглашение, признание иска и другие юридические факты материально-правового значения... Все эти факты могут быть предметом непосредственного познания в суде в силу того, что предмет гражданского процесса - спорное гражданское правоотношение - может продолжать свое развитие (изменение, прекращение) и во время судебного разбирательства».[3, с. 17] Осипов Ю.К. утверждал, что «к числу доказательственных фактов, доступных непосредственному восприятию судей, относятся, в частности, факты, касающиеся поведения заинтересованных лиц в процессе (представление подложного документа, уклонение от явки в суд и другие)».[4, с. 493] Боннер А.Т. тщательно изучив доказательственное значение процессуального поведения сторон, отметил, что «в ряде случаев с теми или иными действиями (бездействием) стороны закон напрямую не связывает каких-либо правовых последствий. В то же время на такого рода факты суд ссылается в своем решении, обосновывая необходимость удовлетворения либо отклонения заявленного требования ... Порой доказательственное значение приобретают не только объяснения, но и поведение лиц, участвующих в деле» $[5$, с. 580].

Думается, что понятие «процессуальное поведение» следует понимать, как действия лиц, участвующих в процессе, направленные на совершение процессуальных действий и имеющие юридическое оформление в виде процессуального документа. Предложенное понятие «процессуальное поведение», как уже было сказано, конечно, не тождественно понятию «улики поведения», так как содержит в себе меньший объем действий, которые совершают участники процесса, и потому, думается, возможно поставить вопрос о тождестве данного понятия с понятием «доказательство». В этом аспекте следует не согласиться с мнением, высказанным Власовым А.А.: «особое, отчасти доказательственное значение имеют данные о поведении участников процесса»; улики поведения, «не подменяя собой доказательств, ... позволяют ... судить об искренности лиц, их истинных намерениях»; «нечто подобное уликам поведения имеет место и в гражданском и арбитражном процессе»; «данные о поведении участников процесса дают возможность лучше судить о качестве излагаемой ими доказательственной позиции». [6, с. 126] И здесь необходимо поставить вопрос, а почему в таком случае процессуальное поведение не может иметь ту же доказательственную силу, что и непосредственно сами доказательства? Чтобы ответить на данный вопрос необходимо привести опре- 
деление доказательств, закрепленное в Гражданском процессуальном кодексе Российской Федерации (далее - ГПК РФ).[7] Доказательствами по делу являются полученные в предусмотренном законом порядке сведения о фактах, на основе которых суд устанавливает наличие или отсутствие обстоятельств, обосновывающих требования и возражения сторон, а также иных обстоятельств, имеющих значение для правильного рассмотрения и разрешения дела. Является ли «процессуальное поведение» сведением о каком - либо факте? Если допустить, что все требования к доказательству, такие как относимость, допустимость, достоверность соблюдены, то да, безусловно, «процессуальное поведение» - это сведение о факте. В принципе, любое действие позволяет нам извлечь информацию разного рода. Например, информацию о субъекте, совершающим это действие, а, если мы уже имеем такую информацию и знаем цели, которые субъект преследует, то возможно и спрогнозировать логику его дальнейшего процессуального поведения.

Вместе с тем, необходимо заметить, что факты процессуального поведения с точки зрения своего доказательственного значения обычно релевантны материально-правовым фактам, утверждаемым стороной, и соответствуют ее позиции по делу.

Вопрос о доказательственном значении процессуальных фактов, образующих системно само процессуальное поведение, может стать особенно актуальным тогда, когда формы такого поведения вступают в диссонанс с материально-правовой позицией стороны спора, т.е. возникает противоречие между поведением лица в материально-правовых отношениях и отношениях процессуальных.

Выше был обозначен тезис о том, что юридические процессуальные факты, выраженные в форме «поведения» лиц, участвующих в процессе, имеют доказательственную силу. Об этом необходимо сказать подробнее, сравнив «процессуальное поведение» с доказательствами.

Итак, в соответствие со ст. 55 ГПК РФ: «. сведения могут быть получены из объяснений сторон и третьих лиц, показаний свидетелей, письменных и вещественных доказательств, аудио- и видеозаписей, заключений экспертов».

Что касается объяснения сторон и третьи лиц, то в ч. 2 ст. 68 ГПК РФ говорится, что: «Признание стороной обстоятельств, на которых другая сторона основывает свои требования или возражения, освобождает последнюю от необходимости дальнейшего доказывания этих обстоятельств. Признание заносится в про- токол судебного заседания. Признание, изложенное в письменном заявлении, приобщается к материалам дела».

Согласно ч. 1 ст. 71 ГПК РФ: «Письменными доказательствами являются содержащие сведения об обстоятельствах, имеющих значение для рассмотрения и разрешения дела ... К письменным доказательствам относятся приговоры и решения суда, иные судебные постановления, протоколы совершения процессуальных действий, протоколы судебных заседаний, приложения к протоколам совершения процессуальных действий (схемы, карты, планы, чертежи)». В данной ситуации при помощи анализа категории «процессуальное поведение», а также при сопоставлении данной категории с категорией «доказательства», а также при сравнении с различными видами доказательств, приходим к выводу, что «процессуальное поведение» имеет одну и туже правовую природу с законодательно закрепленными видами доказательств. Значит, ли это, что «процессуальное поведение» может являться отдельным видом доказательства и его надлежит легально закрепить в действующих процессуальных кодексах? Конечно, нет. Дело в том, что «процессуальное поведение» проявляет себя, соответственно, через различные виды доказательств, в этом и есть его особенность. «Процессуальное поведение» лиц, участвующих в процессе не может являться отдельным видом доказательством, так как оно может воплощаться во всех видах доказательств. Однако «процессуальное поведение» как бы расставляет акценты, и, кажется, делает очевидным разрешение дела. При этом, согласно ч. 2 ст. 67 ГПК РФ: «Никакие доказательства не имеют для суда заранее установленной силы». Особенность такого «процессуального доказательственного поведения» заключается в том, что с его помощью, в том числе, устанавливаются факты материально - правового характера.

О такого рода фактах «процессуального поведения» закон иногда говорит прямо: «В случае, если сторона, обязанная доказывать свои требования или возражения, удерживает находящиеся у нее доказательства и не представляет их суду, суд вправе обосновать свои выводы объяснениями другой стороны» (ч. 1 ст. 68 ГПК РФ). Из данного действия сторон явственно прослеживается связь с фактами материально - правового характера.

Несмотря на все выше сказанное, необходимо заметить, что в юридической литературе наблюдается дискуссия о наличии доказательственного значения за «процессуальным поведением». Так, например, противоположную точку зрения занимает Смольников Д.И.: «поведение лица в процессе не является до- 
казательством, однако это не препятствует его оценке судом». [8, с. 9] Думается, что данный ученый просто входит в противоречие. Как уже было сказано выше, процессуальное поведение лица, может проявить себя через любой вид доказательств и будет, кроме этого, зафиксировано в протоколе судебного заседания. То есть, утверждать, что «поведение лица в процессе не является доказательством» [8, с. 19] - это тождественно утверждению «доказательство не является доказательством».

Тем не менее, постараемся привести более весомы аргументы и обосновать, что «процессуальное поведение» или понятие, думается, ему тождественное «совокупность процессуальных фактов», через которые это поведение выражается, может не просто иметь доказательственное значение, но, по сути, проявлять себя непосредственно через доказательства.

Итак, в процессе может наличествовать ситуация, когда доказывается непосредственно процессуальный факт при помощи факта материально - правового характера. Например, абз. 3 п. 28 Постановления закрепляет: «обязанность доказать наличие обстоятельств, препятствовавших лицу, ссылающемуся на дополнительные (новые) доказательства, представить их в суд первой инстанции, возлагается на это лицо». [9] Также может возникнуть ситуация, когда одни процессуальные юридические факты доказываются при помощи других процессуальных юридических фактов. Примером, может быть абз. 6 п. 28 Постановления, который закрепляет, что «дополнительные (новые) доказательства не могут быть приняты судом апелляционной инстанции, если будет установлено, что лицо, ссылающееся на них, не представило эти доказательства в суд первой инстанции, поскольку вело себя недобросовестно и злоупотребляло своими процессуальными правами». [9] По сути в данных выдержках речь идет о совершении тех или иных процессуальных действиях, объединенных в некую систему, которая в свою очередь образует процессуальное поведение лица.
Во-первых, все действия лица в процессе образуют в своей совокупности процессуальное поведение. Данные действия приобретают статус именно «процессуального поведения» за счет того, что в обязательном порядке находят фиксацию в протоколе судебного заседания. Процессуальное поведение либо воплощается напрямую в каком - либо доказательстве, либо приобретает процессуальную форму исключительно через протокол судебного заседания. И в первом, и во втором случае речь идет о процессуальных юридических фактах.

Во-вторых, данные действия чаще всего воплощаются в доказательствах. Однако стоит заметить, что они также могут воплощаться сразу в нескольких актах поведения лица.

В-третьих, доказательственное значение процессуальное поведение может приобретать только при активной роли противоположной стороны. Лицо, истец либо ответчик, или их представитель в таком случае должны обладать повышенным вниманием к действиям противоположной стороны и иметь должный инструментарий процессуальных средств, то есть обладать глубокими теоретическими знаниями процессуального права.

Значение процессуального поведения велико не только для сторон, а также их представителей, хотя для них его значение первично. Однако, как известно, доказыванием может заниматься также суд. Более того процессуальное поведение становится объектом пристального внимания наиболее часто в суде второй и последующих инстанций. Это достаточно очевидно в силу того, что начиная со второй инстанции процессуальные отношения, которые были очень динамичны в суде первой инстанции, становятся более статичными. Итак, суд второй инстанции, изучая дело, в состоянии анализировать различные факты, обстоятельства в системе, что наиболее важно, чтобы расставить акценты и заметить вектор процессуального поведения.

\section{ЛИТЕРАТУРА}

1. 1 Федеральный закон от 28.11.2018 № 451-Ф3 (ред. от 17.10.2019) «0 внесении изменений в отдельные законодательные акты Российской Федерации».

2. Хмыров А. «Улики поведения» и их роль в доказывании по уголовным делам // Советская юстиция. 1983. N21. С. 5.

3. Курылев С.В. Основы теории доказывания в советском правосудии. Минск: Изд. БГУ им. В.И. Ленина, 1969. С. 17.

4. Осипов Ю.К. 0 допустимости доказательств в советском гражданском процессе. Цит. по: Краткая антология уральской процессуальной мысли: 55 лет кафедре гражданского процесса Уральской государственной юридической академии / Под ред. В.В. Яркова. Екатеринбург: Изд-во Гуманитарного ун-та, 2004. С. 493.

5. Боннер А.Т. Традиционные и нетрадиционные средства доказывания в гражданском и арбитражном процессе: Монография. М.: Проспект, 2013. C. 610 .

6. Власов А.А. Адвокат как субъект доказывания в гражданском и арбитражном процессе. М.: 000 Издательство «Юрлитинформ», 2000. С. 127. 
7. «Гражданский процессуальный кодекс Российской Федерации» от 14.11.2002 № 138-Ф3 (ред. 0т 01.07.2021).

8. Смольников Д.И. Косвенные доказательства в гражданском судопр. России: Автореф. дис. ... канд. юрид. наук. М., 2015. С. 9, 19.

9. Постановления Пленума Верховного Суда РФ от 19.06 .2012 № 13 «0 применении судами норм гражданского процессуального законодательства, регламентирующих производство в суде апелляционной инстанции».

( Р Рокотянская Яна Александровна ( 7726299@mail.ru ).

Журнал «Современная наука: актуальные проблемы теории и практики»
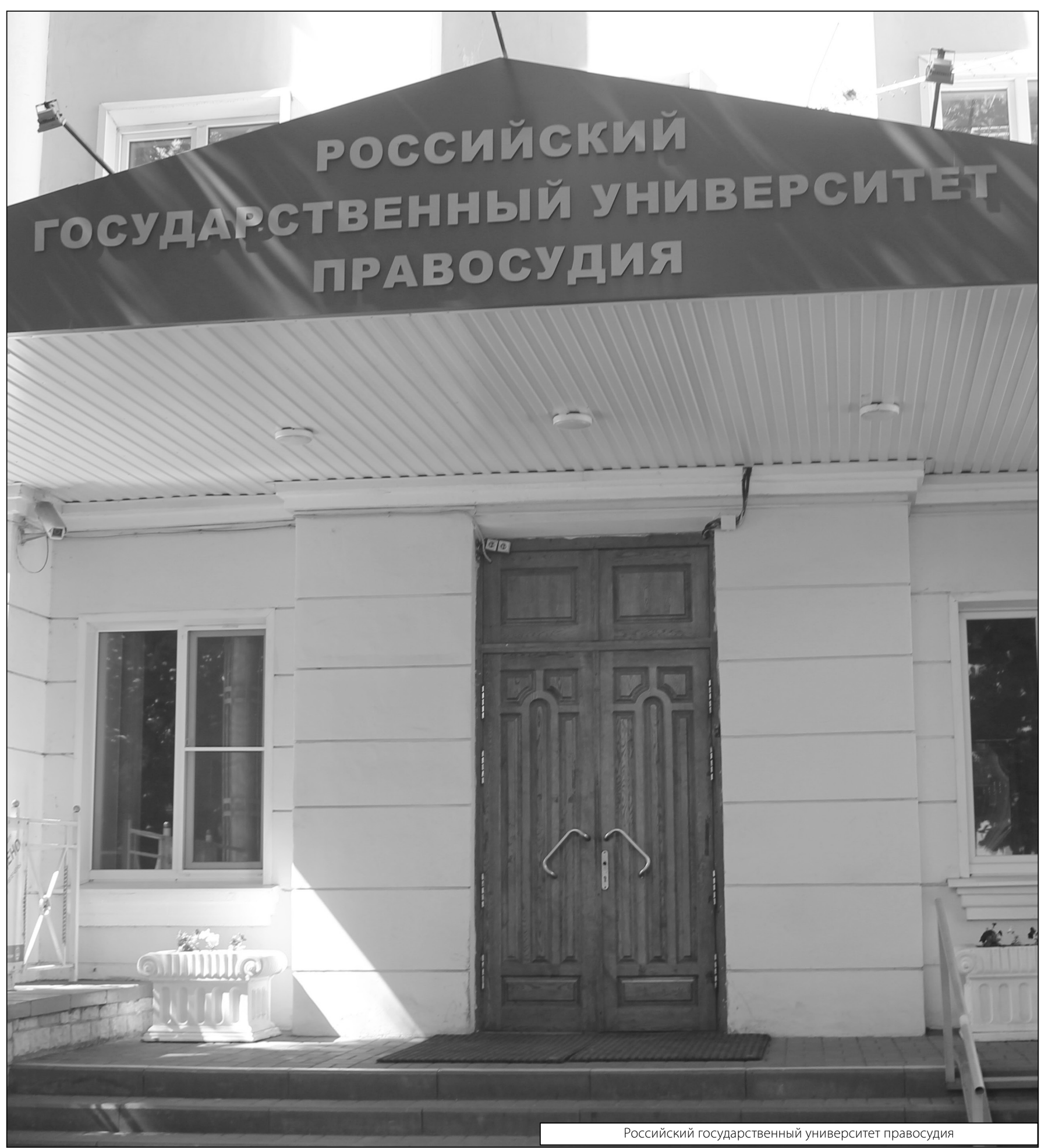